\title{
Management of Devolved Health Services, Democratic Leadership Style and Healthcare Service Delivery in Arid and Semi Arid Lands in Kenya
}

\author{
Abdihafid Abdullahi Yarow ${ }^{1}$, Shadrack Jirma ${ }^{2}$ \& Elijah Siringi ${ }^{3}$ \\ ${ }^{1}$ School of Management and leadership, Management University of Africa, Nairobi, Kenya \\ Correspondence: Abdihafid Abdullahi Yarow, School of Management and leadership, Management University of \\ Africa, Nairobi, Kenya. E-mail: abdi78@gmail.com
}

Received: July 9, 2019

Accepted: August 26, 2019

Online Published: September 28, 2019

doi:10.5539/ijbm.v14n11p1

URL: https://doi.org/10.5539/ijbm.v14n11p1

\begin{abstract}
Devolution was meant to improve efficiency in service delivery in the public healthcare facilities by improving financial allocation, human resource capacity and increasing medical supplies, equipment and health facilities. A glimpse of hope was noted with devolution especially in the ASALs with Mandera undertaking its first caesarean operation since independence and Wajir tripling its maternity facilities within three years. However, 5 years after devolution the neonatal mortality and maternal mortality still remain high. The purpose of this study was to investigate the moderating effect of democratic leadership style on the relationship between management of devolved health services and health-care service delivery in Arid and Semi-Arid Lands in Kenya. This study was guided by fiscal decentralization theory, participation theory and theory of performance improvement, as well as sequential theory of decentralization. This study used a triangulation of both positivism and phenomenology. The population under this study constitute the Sub-Counties in ASAL in Kenya with a sample size of 89 Sub-Counties being sampled and 3 patients from each of the 89 sampled sub counties. Given the findings, did not accept the null hypothesis ( $\mathrm{H} 0)$ and therefore concludes that democratic leadership style has a significant moderating effect on the relationship between management of devolved health services and health-care service delivery in Arid and Semi-Arid Lands in Kenya. Therefore, hospitals management should come up with strategies that can help improve financial resources to fund facilities improvement and purchase of equipment and supplies. These strategies can include seeking for donor funding among others.
\end{abstract}

Keywords: management of devolved health services, democratic leadership style, healthcare service delivery

\section{Introduction}

The concept of devolution involves the transfer of authority and power over public service delivery from central government to a semi-autonomous sub-national structure, which aids in the management, decision-making, and public planning (Diana et al., 2014). It is the statutory delegation of powers from the central government of a sovereign state to govern at a sub-national level, such as a regional or local level. It is also a form of administrative decentralization or the transfer of authority and responsibility from central to lower levels of government for a range of public functions including health care (Okech, 2017). Devolved territories have the power to make legislation relevant to the area meaning that the units have clear and legally recognized geographical boundaries over which they exercise authority and within which they perform their functions in their respective jurisdictions.

Worldwide, there has been a trend in the devolution of authority in healthcare whereby the authority that was often sitting with one central Ministry or Department of Health devolved over time (KPMG, 2015; Okech, 2017). There has been a global trend to decentralize the public health sector, from the central government to the county government, or from large hospitals to district hospitals (Cheshire, 2010). Devolution has been successful in some parts of the world for instance United States, India, Nigeria, Sweden, United Kingdom and South Africa are some of the countries where devolution has delivered the expected results in terms of political stability and development (Voon et al., 2011). Wangari (2014) argued that devolution has both an explicit and implicit motivation of improving service delivery for two reasons; first the basic services which the state is responsible for are systematically failing. Secondly, improving service delivery through devolution is important because 
these services are consumed locally. At Global level, devolution has been at the center of sudden rise of economic development in many developing countries such as China, Nepal and Chile among others (Mayoka et al., 2014).

In Africa devolution is practiced in South Africa, Uganda, Ethiopia, Tanzania, Nigeria, Ghana and now, Kenya among many other (Amusa \& Mabugu, 2016). For instance, in Uganda, devolution is practiced through Kingdoms while in Tanzania devolution is through Jimbos (Voon et al., 2011). There is paucity of studies that have examined devolution experiences across the Africa region in a comprehensive and comparative way (Batchelor et al., 2018).

In practice, devolution grants the devolved governments the capacity to develop policies that are better tailored to the economic and social conditions of their areas, encouraging policy divergence through the introduction of "local solutions to local problems" (Mackinnon, 2015). Moreover, Mackinnon (2015) indicated that devolution creates logic of inter-territorial comparison and competition, potentially resulting in policy learning and transfer as the different administrations monitor developments elsewhere, adopting successful or popular policies from other jurisdictions. However, Yusoff, Sarjoon, Awang, and Efendi (2016) contend that in devolution, powers are transferred to autonomous units governed independently and separately without the direct control of central government.

According to Scheffler, Bruckner and Spetz (2012), assessing the health labour market requires to study both the demand and the supply sides, and how to match them in order to determine shortages (or surpluses) of health workers. The supply of health workers includes leadership style and the number of qualified health workers willing to work at a given wage rate in the health care sector (physicians, nurses and other care providers). Thus, leadership style is key determinants in health-care service delivery for devolved systems. One of the leadership styles to manage this momentum is democratic leadership style is where the leader engages others in identifying the important goals and formulating strategies to attain the goals (Iqbal, Anwar \& Haider, 2015). This means County leaders using this approach will ensure all the stakeholders in healthcare service delivery are engaged in the execution of healthcare service delivery projects.

This paper was guided by the following null hypothesis hypothesis:

HO: Democratic leadership style does not significantly moderate the relationship between management of devolved health services and health-care service delivery in Arid and Semi-Arid Lands in Kenya.

\section{Method}

This section explained the methodology to be applied in this research.

\subsection{Research Philosophy and Design}

This study used a triangulation of both positivism and phenomenology using questionnaire-based surveys, observation, and secondary sources, which further makes the approach best suited for this study. Thus, the notion of open-ended questions and conversational inquiry allowed research participants to talk about the topic in their own words, free of the constraints imposed by fixed-response questions that are generally seen in quantitative methods. In addition, this study used both descriptive survey research design and explanatory research design to help identify, analyze, and describe management of devolved health services, leadership style, in-service training and health-care service delivery in arid and semi-arid lands in Kenya. Descriptive survey design was used to allow for description of devolution, leadership style and health care service delivery. Previous studies by Abe and Monisola (2014), Macharia et al., (2014), Opiyo (2014) and Wangari (2014) examined the relationship between devolution and service delivery and used the descriptive design. Several previous studies on decentralization and service delivery have used explanatory research design with satisfactory results (Adam et al., 2012; Alaaraj \& Ibrahim, 2014).

\subsection{Population}

The population under this study constitute the Sub-Counties in ASALs in Kenya. According to the Ministry of Planning and Devolution Report (2016), there are one hundred and thirteen (113) Sub-Counties demarcated as Arid and Semi-Arid Lands (ASAL) and distributed within 23 counties in Kenya. The Ministry further categorises the 113 Sub-Counties into Arid (36 Sub-Counties in 8 counties) and Semi-Arid (77 Sub-Counties in 15 counties).

\subsection{Sample and Sampling Technique}

A sample is a small proportion of targeted population selected. In cases where a census (a survey of the entire population) is impossible, sampling procedures provide a justified option (Kothari, 2004). In this regard 
sampling of the ASAL Sub-Counties was done using the Slovin's Formula (as used by Ariola, 2006). The formula is expressed as $\mathrm{n}=\mathrm{N} /\left(1+\mathrm{Ne}^{2}\right)$.

Where: $\mathrm{n}$ is sample size; $\mathrm{N}$ is the population size and $\mathrm{e}$ is the tolerance error. The confidence level gives the margin of error; in this formula, it ranges from $95 \%$ to $99 \%$ implying a tolerance error of 0.05 and 0.01 respectively (Ariola, 2006). The current study used a $95 \%$ confidence level implying a 0.05 tolerance error. Therefore, using Slovin's Formula, the sample size was calculated as: $\mathrm{n}=113 /\left(1+113(0.05)^{2}\right)=88.11 \approx 89$ sub-counties.

Proportionate sampling was then used to allocate the proportion of the sample size going to each of the 23 counties. Kothari (2004) noted that proportionate sampling is used when a population from which sample is to be drawn does not constitute a homogeneous group. Proportionate sampling involves dividing the population into a series of relevant proportions which implies that the sample is likely to be representative. Sub-counties which form our population are characterized by heterogeneous groups, given that some fall in Arid Lands while others are in Semi-Arid Lands. Proportions for this study were effectively applied at county level where the number of sub-counties in each county formed the proportion of sample size going to the county. Random sampling was then applied to select sub-counties. The proportions used were computed as Proportion $(\mathrm{P})=$ Sample Size/Total population $=89 / 113=0.787611$. Respondents for this study comprised of two categories. The first category included 89 Sub County Health Managers with the second category comprising of 3 patients from each of the 89 sampled sub counties. Random sampling was used to select patients at the selected Sub county hospitals. This ensured those sampled would not be strained during the interviews. The total number of respondents was therefore calculated as 89 sub-county health managers plus 267 (3 X 89) patients which yielded a total of 356 respondents. This ensured a naturally heterogeneous but relatively homogeneous sample as recommended by Saifuddin (2009).

\subsection{Data Collection Instruments}

The data collection instruments were questionnaires and interview guides. Kothari (2004) defines a questionnaire as a document that consists of a number of questions printed or typed in a definite order on a form or set of forms.

\subsection{Data Collection Procedure}

In this study, primary data was collected through questionnaires and interview guides. The researcher trained four research assistants who was engaged in collecting primary data. Secondary data was collected by the researcher himself from records obtained from the respective counties and related to issues on health-care service delivery. This was done by first seeking authority from the relevant county and sub-county authorities in ASALs, Management University of Africa and National Commission for Science Technology and Innovation (NACOSTI). For purposes of collecting data in this study, the questionnaire and interview guide was administered to the relevant respondents in the institutions by research assistants and filled by the selected respondents. The filled questionnaires and interview guides were brought to the researcher for analysis.

\subsection{Validity and Reliability Tests}

The researcher carried out a pilot study to pre-test the validity and reliability of data collected using the questionnaire that was administered to 10 healthcare staff in one county within ASAL. The clarity of the instrument items was necessary so as to enhance the instrument's validity and reliability. The aim was to correct inconsistencies arising from the instruments, which ensures that they measure what is intended. The pilot data was not included in the actual study. For this study, the researcher used expert judgment to determine whether there was any ambiguity in any information and if any it was adjusted or corrected.

The reliability was tested for internal consistency using the Cronbach alpha coefficient. The rationale for internal consistency is that the individual items should all be measuring the same constructs and thus correlates positively to one another (Kipkebut, 2010). The Alpha can take any value from zero (no internal consistency) to one (complete internal consistency). Nunnally (1978) suggested that as a rule of thumb, scores in the ranges $0.5-0.6$, $0.6-0.7,0.7-0.8$, and $0.8-0.9$, should be considered to have an internal consistency that is poor, questionable, acceptable or good, respectively. Values above 0.9 represent excellent internal consistency, while values less than 0.5 are considered to be unacceptable. This study found an average alpha of 0.83 and thus the research instruments were found to be consistent.

Data collected was first checked on the level of response before actual data analysis is undertaken using IBM SPSS version 24 and Microsoft excel. Those whose levels of response were found to be adequate was assigned numbers for coding into the computer. Then the data collected was subjected to qualitative and quantitative 
analysis. With respect to this, the quantitative data was categorized according to subject concept of the objectives of this study. The organized data was then interpreted in the light of the research problem to be addressed and used to enhance the quantitative findings.

Quantitative analysis entailed computing descriptive statistics like the frequency and percentage for the quantitative data. Measures of central tendency were also used in which case the mean and the mode were computed. At the same time, measures of dispersion were computed particularly the standard deviation. Inferential statistics were all applied on the quantitative data where correlation analysis, analysis of variance (ANOVA) and regression analysis was done. Presentation of findings shall be done using tables, pie charts, bar graphs as well as histograms for interpretation, summary and conclusions. In conducting the regression analysis, simple and multiple linear regressions analysis done in which case, the regression was done at different levels. Qualitative findings on the other hand were derived from in-depth interviews (IDIs) that were conducted with beneficiaries of health services in ASAL. Analysis was done using R-based Qualitative Data Analysis (RQDA) software and results presented in bar plots and word clouds.

\section{Results}

Results were presented based on the two variables, that is, management of devolved health services, and healthcare service delivery

\subsection{Management of devolved health Services}

Table 1. Descriptive statistics for management of devolved health service

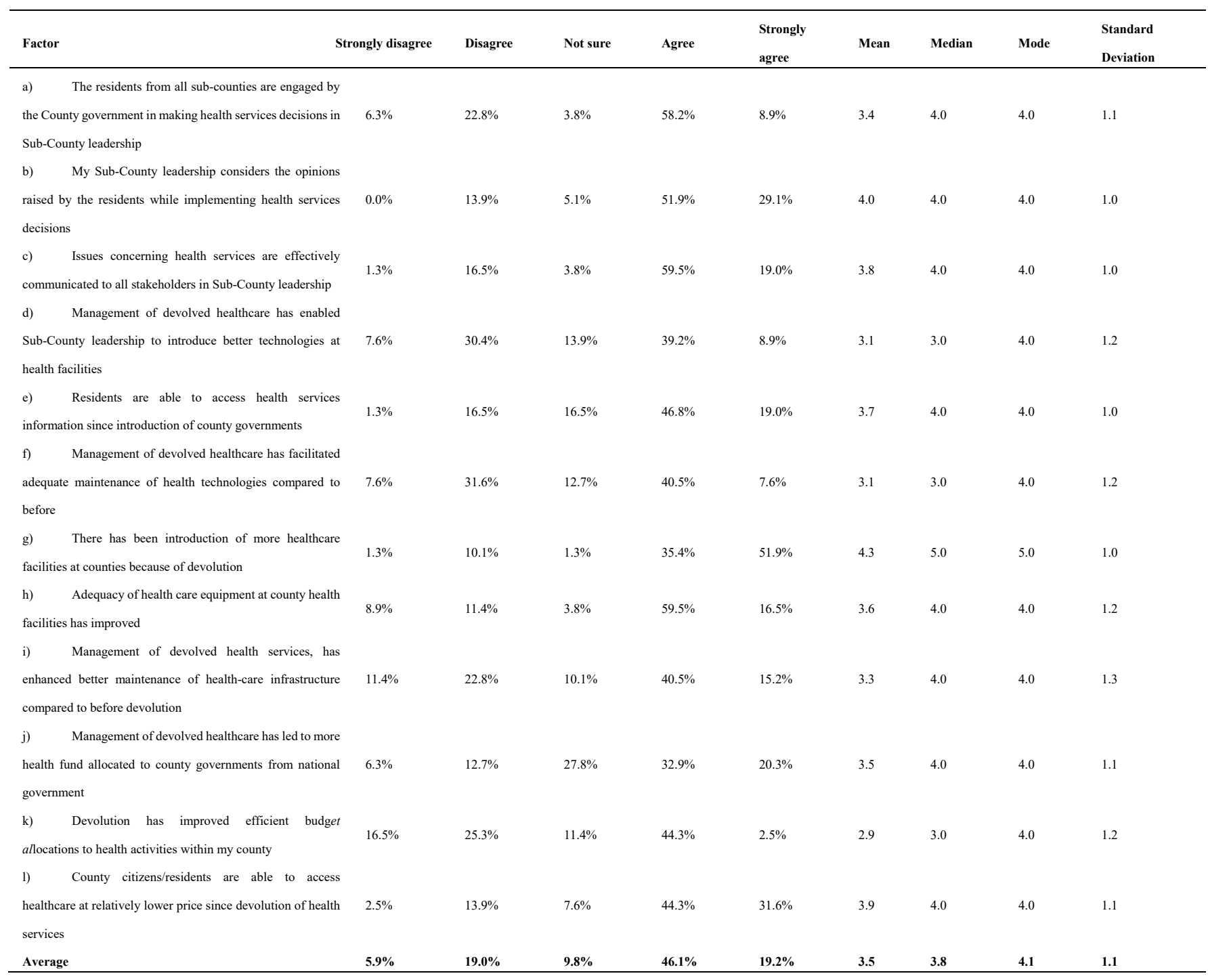


As shown in Table 1, respondents strongly agreed that there has been introduction of more healthcare facilities at counties in ASAL resulting from devolution (mean $=4.3$, mode $=5.0$, median $=5.0$, standard deviation $=1.0$ ). At the same time findings revealed that sub-County leaderships have been largely considering the opinions raised by the residents while implementing health services decisions (mean $=4.0$, mode $=4.0$, median $=4.0$, standard deviation $=1.0$ ) while allowing them (citizens/residents) to access healthcare at relatively lower price since devolution of health services (mean $=3.9$, mode $=4.0$, median $=4.0$, standard deviation $=1.1$ ). It was as well noted that issues concerning health services are at a effectively but at a moderate level communicated to all stakeholders in sub-County leadership (mean $=3.8$, mode $=4.0$, median $=4.0$, standard deviation $=1.0$ ) with residents are able to access health services information since introduction of county governments $($ mean $=3.7$, mode $=4.0$, median $=4.0$, standard deviation $=1.0$ ).

Respondents, nonetheless, expressed reservations regarding whether management of devolved healthcare has enabled sub-County leadership to introduce better technologies at health facilities as given by an unresolved mean of 3.1 and mode of 3.0 but with high median of 4.0 and standard deviation $=1.2$. Respondents also disagreed that, devolution has facilitated adequate maintenance of health technologies compared to before (mean $=3.1$, mode $=3.0$, median $=4.0$, standard deviation $=1.2$ ) as well as moderately dissenting that devolution has improved efficient budget allocations to health activities within my county ( mean $=2.9$, mode $=3.0$, median $=$ 4.0, standard deviation =1.2). Based on the average, management of devolved health services had mean of 3.5 with mode, median and standard deviation of 3.8, 4.1 and 1.1 respectively implying that respondents agreed on most of the constructs of management of devolved health services in ASAL. While devolution has brought healthcare services nearer to the residents, the county government has nonetheless not been able to adequately meet budget requirements.

\subsection{Democratic Leadership Style}

Descriptive statistics for leadership style was based on 4 constructs as presented in Table 2.

Table 2. Descriptive statistics for leadership style

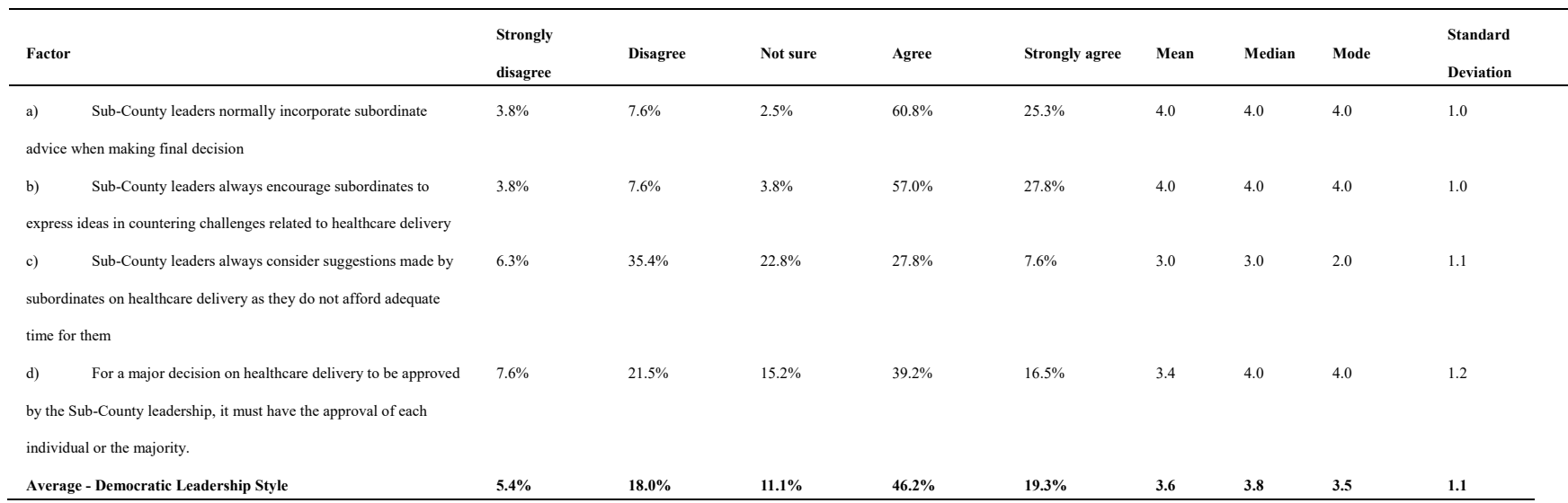

Findings in Table 2 indicate that Sub-County leaders normally incorporate subordinate advice when making final decision and always encourage subordinates to express ideas in countering challenges related to healthcare delivery $($ mean $=4.0 ;$ mode $=4.0 ;$ median $=4.0$; standard deviation 1.0 ). Average mean was 3.6 implying that democratic leadership style is employed by county leadership in ASAL to a great extent.

\subsection{Health-Care Service Delivery}

Descriptive statistics for health-care service delivery was based on nine (9) constructs as presented in Table 3. 
Table 3. Descriptive statistics for health-care service delivery

\begin{tabular}{|c|c|c|c|c|c|c|c|c|c|}
\hline Factor & $\begin{array}{l}\text { Strongly } \\
\text { disagree }\end{array}$ & Disagree & Not sure & Agree & $\begin{array}{l}\text { Strongly } \\
\text { agree }\end{array}$ & Mean & $\begin{array}{l}\text { Media } \\
\text { n }\end{array}$ & Mode & $\begin{array}{l}\text { Standard } \\
\text { Deviation }\end{array}$ \\
\hline $\begin{array}{l}\text { a) As a result of management of devolved } \\
\text { health services, healthcare facilities and services are } \\
\text { now accessible to residents. }\end{array}$ & $0.0 \%$ & $7.6 \%$ & $5.1 \%$ & $62.0 \%$ & $25.3 \%$ & 4.1 & 4.0 & 4.0 & 0.8 \\
\hline $\begin{array}{l}\text { b) In the last five years the quality of the health } \\
\text { services at county health centers has greatly } \\
\text { improved }\end{array}$ & $0.0 \%$ & $26.6 \%$ & $12.7 \%$ & $49.4 \%$ & $11.4 \%$ & 3.5 & 4.0 & 4.0 & 1.0 \\
\hline $\begin{array}{l}\text { c) Am satisfied with health services provided } \\
\text { by county health centers }\end{array}$ & $3.8 \%$ & $36.7 \%$ & $6.3 \%$ & $45.6 \%$ & $7.6 \%$ & 3.2 & 4.0 & 4.0 & 1.1 \\
\hline $\begin{array}{l}\text { d) Healthcare complaints from residents have } \\
\text { easily been handled by county government } \\
\text { compared to before }\end{array}$ & $3.8 \%$ & $31.6 \%$ & $11.4 \%$ & $45.6 \%$ & $7.6 \%$ & 3.2 & 4.0 & 4.0 & 1.1 \\
\hline $\begin{array}{l}\text { e) Am satisfied with healthcare programs } \\
\text { introduced by the county government }\end{array}$ & $3.8 \%$ & $28.2 \%$ & $15.4 \%$ & $47.4 \%$ & $5.1 \%$ & 3.2 & 4.0 & 4.0 & 1.0 \\
\hline $\begin{array}{l}\text { f) Healthcare delivery has been more efficient } \\
\text { since devolution of health services compared to } \\
\text { before }\end{array}$ & $6.3 \%$ & $26.6 \%$ & $17.7 \%$ & $39.2 \%$ & $10.1 \%$ & 3.2 & 3.0 & 4.0 & 1.1 \\
\hline $\begin{array}{l}\text { g) Prompt attention is always given to the } \\
\text { patient who visits county government health centers } \\
\text { or hospitals }\end{array}$ & $3.8 \%$ & $17.7 \%$ & $17.7 \%$ & $48.1 \%$ & $12.7 \%$ & 3.5 & 4.0 & 4.0 & 1.1 \\
\hline $\begin{array}{l}\text { h) Drugs are always provided to the patients in } \\
\text { the hospitals or county government health centers }\end{array}$ & $6.3 \%$ & $25.3 \%$ & $13.9 \%$ & $49.4 \%$ & $5.1 \%$ & 3.2 & 4.0 & 4.0 & 1.1 \\
\hline $\begin{array}{l}\text { i) Cost of Health Care Services have reduced } \\
\text { significantly }\end{array}$ & $2.5 \%$ & $21.5 \%$ & $6.3 \%$ & $45.6 \%$ & $24.1 \%$ & 3.7 & 4.0 & 4.0 & 1.1 \\
\hline Average & $3.4 \%$ & $24.6 \%$ & $11.8 \%$ & $48.0 \%$ & $12.1 \%$ & 3.4 & 3.9 & 4.0 & 1.0 \\
\hline
\end{tabular}

Findings as presented in Table 3 shows that, management of devolved health services has greatly made health facilities and services more accessible to residents compared to before (mean $=4.1$, mode $=4.0$, median $=4.0$, standard deviation $=0.8$ ). In addition, the previous five years has recorded great improvement in the quality of the health services at county health centers (mean $=3.5$, mode $=4.0$, median $=4.0$, standard deviation $=1.0$ ) with respondents fairly satisfied with health services provision by county health centers $($ mean $=3.2$, mode $=4.0$, median $=4.0$, standard deviation $=1.1$ ).

Based on average, mean was found to be 3.4, median 3.9, mode (4.0) and standard deviation (1.1). Findings confirmed that management of devolved health services has resulted to better healthcare facilities and with healthcare services being more accessible to residents as well as cost of health care services having reduced significantly. Despite these improvements, residents are not adequately satisfied with some health services especially on handling of healthcare complaints from residents by county government compared to before, healthcare programs introduced by the county government. Availability of drugs in health facilities was also found to a major inefficient side of management of devolved health services.

\subsection{Test for Normality and Homoscedasticity}

\subsubsection{Test for Normality}

Normality test was used to assess whether sample data had been drawn from a normally distributed population. This assessment was important since normal data is an underlying assumption in parametric testing. The test was achieved using Normal Q-Q plot and One-Sample Kolmogorov-Smirnov Test 


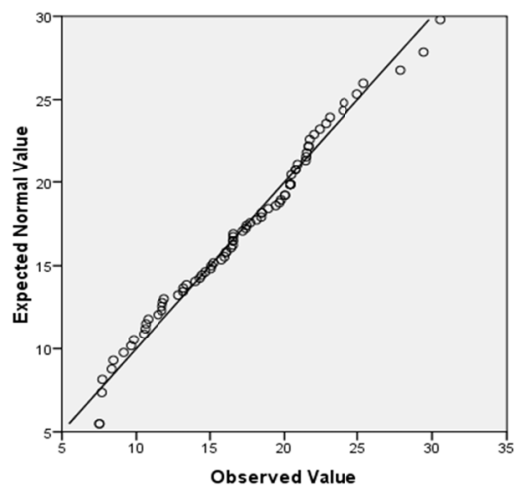

Figure 1. Normal Q-Q plot of health-care service delivery

The output of a normal Q-Q plot was used to determine normality graphically. If the data are normally distributed, the data points will be close to the diagonal line. If the data points stray fromn the line in an obvious non-linear fashion, the data are not normally distributed. As shown in Figure 1, the data is normally distributed.

Table 4. One-Sample Kolmogorov-Smirnov test

\begin{tabular}{lll}
\hline & & Health Care Service Delivery \\
\hline $\mathrm{N}$ & & 79 \\
Normal Parameters & Mean & 17.0543 \\
& Std. Deviation & 5.27971 \\
Most Extreme Differences & Absolute & 0.069 \\
& Positive & 0.064 \\
& Negative & -0.069 \\
Kolmogorov-Smirnov Z & & 0.61 \\
Asymp. Sig. (2-tailed) & & 0.85 \\
Test distribution is Normal. & & \\
\hline
\end{tabular}

The difference between the observed distribution and a perfectly normal one is checked based on a p-Value. If the $\mathrm{p}$-Value is less than 0.05 , the distribution is significantly different from a normal distribution and might be cause for concern. If it is 0.05 or higher, there is no significant difference from normality. As shown in Table 4 , the data for management of devolved health services was normally distributed as p-Value was greater than 0.05 for healthcare service delivery with overall $\mathrm{p}$-Value using Kolmogorov-Smirnova normality index being $0.85>0.05$. Thus, the sample data for this study had been drawn from a normally distributed population. This assessment was important since normal data is an underlying assumption in parametric testing.

\subsubsection{Test for Homoscedasticity}

One of important assumptions of linear regression is that the variance of error term is constant across observations. If the error has constant variance, then the errors are said to be homoscedastic, otherwise heteroscedastic. In case of heteroscedastic errors (non-constant variance), the standard estimation methods become inefficient.

Table 5. Breusch - Pagan Test for Homoscedasticity

\begin{tabular}{lll}
\hline Breusch -Pagan Test Statistic & Degrees of Freedom & p-Value \\
\hline 0.202 & 1 & 0.653 \\
\hline
\end{tabular}

In this study, Breusch-Pagan test (named after Trevor Breusch and Adrian Pagan) was used to test for homoscedasticity. For Breusch-Pagan test the null hypothesis assumes homoscedasticity which is stated as follows:

Null Hypothesis $\left(\mathrm{H}_{0}\right)$ : The data (residuals) is homoscedastic 
Alternative Hypothesis $\left(\mathrm{H}_{1}\right)$ : The data is heteroscedastic

The decision rule is:

If $\mathrm{p}$-Value $<\alpha$; then null hypothesis is rejected.

If $\mathrm{p}$-Value $>\alpha$; then we fail to reject the null hypothesis.

Where $\alpha$ is the level of significance (alpha)

Test for homoscedasticity in this study generated a p-Value of 0.653 (Table 5) and therefore we fail to reject the null hypothesis and conclude that the data (residuals) is homoscedastic.

3.5 Moderating Effect of Democratic Leadership Style on the Relationship between Management of devolved health Services and Healthcare Service Delivery

The moderating effect of democratic leadership style was assessed and results explained using coefficient of determination (R-Square), Analysis of Variance (ANOVA) as well as the regression coefficients. Hierarchical regression analysis was performed with an interaction term (a product of democratic leadership style and management of devolved health services) introduced as an additional predictor.

Table 6. Regression Coefficients when Democratic Leadership Style is Moderating the Relationship between Management of Devolved Health Services and Healthcare Service Delivery

\begin{tabular}{|c|c|c|c|c|c|c|}
\hline \multirow[t]{2}{*}{ Model } & & \multicolumn{2}{|c|}{ Unstandardized Coefficients } & \multirow{2}{*}{$\begin{array}{l}\text { Standardized } \\
\text { Coefficients } \\
\text { Beta }\end{array}$} & \multirow[t]{2}{*}{$\mathrm{t}$} & \multirow[t]{2}{*}{ Sig. } \\
\hline & & B & Std. Error & & & \\
\hline \multirow[t]{3}{*}{1} & (Constant) & 1.254 & 1.535 & & .817 & .416 \\
\hline & Management of devolved health services & .630 & .056 & .785 & 11.179 & .000 \\
\hline & Democratic leadership style & .176 & .160 & .077 & 1.101 & .275 \\
\hline \multirow[t]{4}{*}{2} & (Constant) & -7.473 & 4.165 & & -1.794 & .077 \\
\hline & Management of devolved health services & 1.057 & .198 & 1.318 & 5.339 & .000 \\
\hline & Democratic leadership style & 1.274 & .513 & .561 & 2.482 & .015 \\
\hline & Devolution.Democratic & -.053 & .023 & -.833 & -2.245 & .028 \\
\hline
\end{tabular}

Table 6 presents regression coefficients and their significant values for both model 1 (without interaction term) and model 2 (with interaction term). From the unstandardized coefficients, management of devolved health services was found to have a unique significant and positive contribution to healthcare service delivery regardless of its interaction with democratic leadership style (p-Value $<0.05$ for both models). The same case applied to democratic leadership style which has significant influence on healthcare service delivery but only when interacted with the other predictor, that is management of devolved health services $(b=1.274$, $p$-Value $=0.015<0.05)$. Findings, however, shows a negative relationship between the interaction term (product of management of devolved health services and democratic leadership style) and healthcare service delivery where an increase in 1 unit of interaction term would lead to a decrease in healthcare service delivery by 0.053 , a change that is significant given $\mathrm{p}$-Value $=0.028<0.05$. This also implies that, the more positive becomes the effect of democratic leadership style on healthcare service provision, the more negative effect of management of devolved health services on healthcare service provision becomes. The autonomous value would also be negative (-7.743). Regression model can therefore be summarized as:

$$
Y=-7.743+1.057 X+1.274 W_{2}-0.053 X * W
$$

Where $\mathrm{X}^{*} \mathrm{~W}$ represents interaction term given as a product of democratic leadership style $(\mathrm{W})$ is interacted with management of devolved health services (X) 
Table 7. Analysis of Variance when Democratic Leadership Style is Moderating the Relationship between Management of Devolved Health Services and Healthcare Service Delivery

\begin{tabular}{lllllll}
\hline Model & Sum of Squares & df & Mean Square & F & Sig. \\
\hline 1 & Regression & 1433.117 & 2 & 716.559 & 73.477 & .000 \\
& Residual & 741.159 & 76 & 9.752 & & \\
& Total & 2174.276 & 78 & & 53.270 & .000 \\
2 & Regression & 1479.800 & 3 & 493.267 & & \\
& Residual & 694.476 & 75 & 9.260 & & \\
& Total & 2174.276 & 78 & & & \\
\hline
\end{tabular}

The ANOVA (Table 7) was intended to evaluate if models 1 and 2 are significant and if the amount of variance accounted for in Model 2 (with the interaction) is significantly more than Model 1 (without the interaction). Findings indicate that the model as a whole (which includes both blocks of variables) is significant given $\mathrm{F}(2,76$ ) $=73.477, \mathrm{p}$-Value $=0.000<0.05$ for model 1 and $\mathrm{F}(3,75)=53.270, \mathrm{p}$-Value $=0.000<0.05$ for model 2.

Table 8. Coefficient of Determination when Democratic Leadership Style is Moderating the Relationship between Management of Devolved Health Services and Healthcare Service Delivery

\begin{tabular}{|c|c|c|c|c|c|c|c|c|c|}
\hline \multirow[b]{2}{*}{ Model } & \multirow[b]{2}{*}{$\mathrm{R}$} & \multirow[b]{2}{*}{$\mathrm{R}^{2}$} & \multirow[b]{2}{*}{ Adjusted $\mathrm{R}^{2}$} & \multirow{2}{*}{$\begin{array}{l}\text { Std. Error of the } \\
\text { Estimate }\end{array}$} & \multicolumn{5}{|c|}{ Change Statistics } \\
\hline & & & & & $\mathrm{R}^{2}$-Change & F-Change & df1 & $\mathrm{df} 2$ & $\begin{array}{l}\text { Sig. } \\
\text { F-Change }\end{array}$ \\
\hline 1 & $.812^{a}$ & .659 & .650 & 3.123 & .659 & 73.477 & 2 & 76 & .000 \\
\hline 2 & $.825^{\mathrm{b}}$ & .681 & .668 & 3.043 & .021 & 5.042 & 1 & 75 & .028 \\
\hline
\end{tabular}

Table 8 presents the percent of variability in the healthcare service provision (dependent variable) that can be accounted for by management of devolved health services and democratic leadership style (predictors). In model 1 where interaction term was not included, $\mathrm{R}^{2}$ was found to be 0.659 with a standard error of 3.123 implying that management of devolved health services and democratic leadership style accounted for 65.9 percent of the variation in healthcare service delivery. With introduction of interaction term, $\mathrm{R}^{2}$ increases by 0.021 to 0.681 with standard error reducing to 3.043. This increase was significant implying that democratic leadership style had a significant moderating effect on the relationship between management of devolved health services and health-care service delivery.

To test the hypothesis that democratic leadership style does not significantly moderate the relationship between management of devolved health services and health-care service delivery in Arid and Semi-Arid Lands in Kenya, a hierarchical multiple regression analysis was conducted. In the first step, two variables were included: management of devolved health services and democratic leadership style. These variables accounted for a significant amount of variance in healthcare service delivery, $\mathrm{R}^{2}=0.650, \mathrm{~F}(2,76)=73.477, \mathrm{p}$-Value $0.000<$ 0.05. Next, the interaction term between management of devolved health services and democratic leadership style was added to the regression model, which accounted for a significant proportion of the variance in healthcare service delivery even though the unique contribution of management of devolved health service on healthcare service delivery would be significantly reduced when democratic leadership style becomes more, $\Delta \mathrm{R}^{2}$ $=0.021, \Delta \mathrm{F}(1,75)=5.042, \mathrm{~b}=-0.053, \mathrm{t}(75)=-2.245, \mathrm{p}$-Value $=0.028<0.05$. Consequently, the researcher did not accept the null hypothesis $\left(\mathrm{H}_{2 \mathrm{~b}}\right)$ and therefore concludes that democratic leadership style has a significant moderating effect on the relationship between management of devolved health services and health-care service delivery in Arid and Semi-Arid Lands in Kenya.

\subsection{Qualitative Findings}

Qualitative findings were derived from in-depth interviews (IDIs) that were conducted with beneficiaries of health services in ASAL. Analysis was done using R-based Qualitative Data Analysis (RQDA) software and results presented in bar plots and word clouds. This was achieved by visual representation of text data in the form of tags and whose frequency of occurrence indicated level of prevalence as visualized by bar size, text size, text weight as well as the text color.

\subsubsection{Communities Involved in Health Care Service Delivery}

This section was intended to complement findings on leadership style by county leadership in ASAL. Bar plot of 
most occurring adjectives and word cloud were used to present responses on communities' involvement in health care service delivery as shown in Figures 2 and 3.

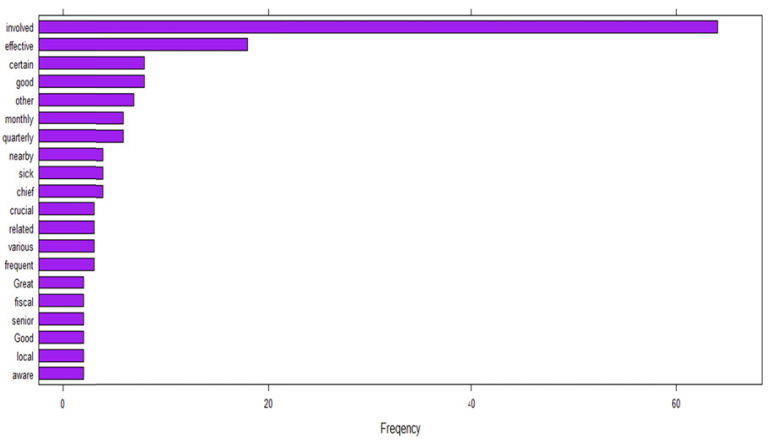

Figure 2. Bar plot of most occurring adjectives on communities involvement in health care service delivery

Figure 2 presents the bar plot of most occurring adjectives on communities' involvement in health care service delivery. The plot indicates involvement of communities have not only been existing but has also been effective. Interviewees noted that there has been great involvement of community healthcare service delivery after devolution through communities' participation when meeting to select projects for fiscal years and establishment of community units where facility management committee and health workers normally hold meeting on monthly or quarterly bases. It was also revealed that, this involvement has been very effective because it is made through facility management committee hospital board as well as frequent community meeting in the community units

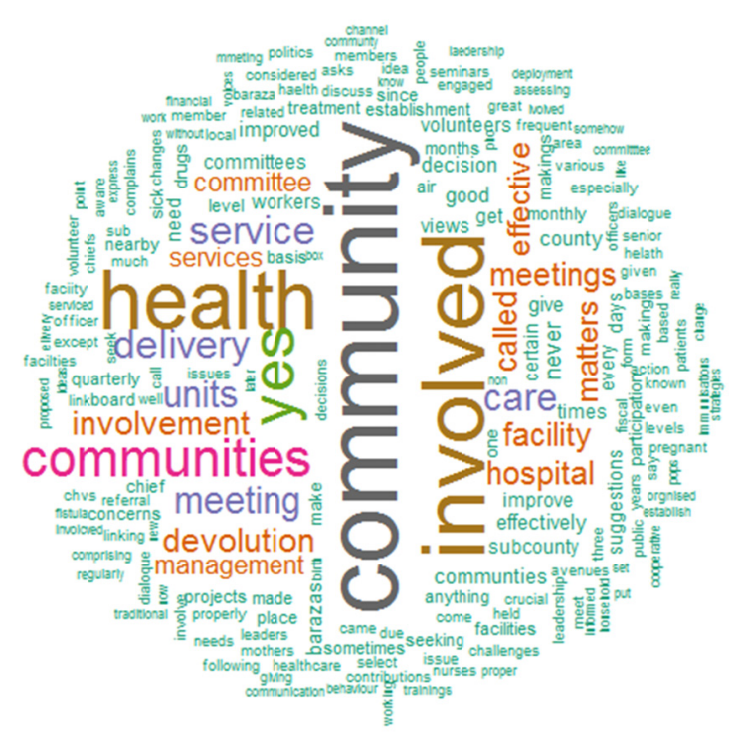

Figure 3. Word cloud on communities involvement in health care service delivery

Figure 3 illustrates word cloud on communities' involvement in health care service delivery and confirms findings in Figure 2 that communities are involved in healthcare service delivery in arid and semi-arid areas. Other most noticeable texts include effective, committee, involvement and meeting implying that communities are to a great extent involved in healthcare service delivery

\subsubsection{Devolution in Health Services and Improvement in Healthcare Service Delivery}

This section presents contribution of devolution in health services in healthcare service delivery. Figure 4 addresses this by establishing whether management of devolved health services has led to improvement in 
healthcare service delivery in respondent's county. Word cloud on aspects of healthcare service delivery that have improved as a result of management of devolved health services is also presented in Figure 5.

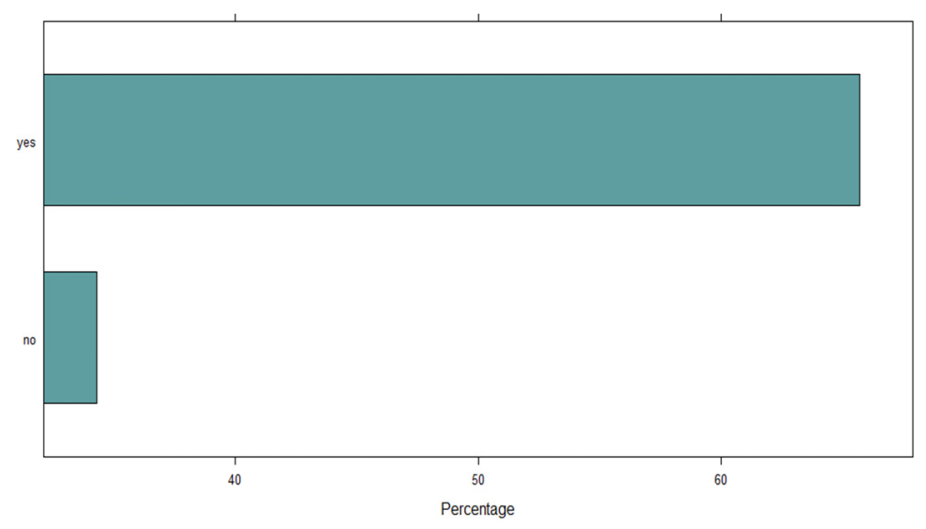

Figure 4. Whether management of devolved health services has led to improvement in healthcare service delivery in respondent's county

As shown in Figure 4, over 70 percent of respondents indicated their satisfaction on management of devolved health services expressing that the devolved governance has led to improvement in healthcare service delivery in ASAL. Less than 30 percent were however of different opinion and negated contribution of management of devolved health service in improving healthcare service delivery.

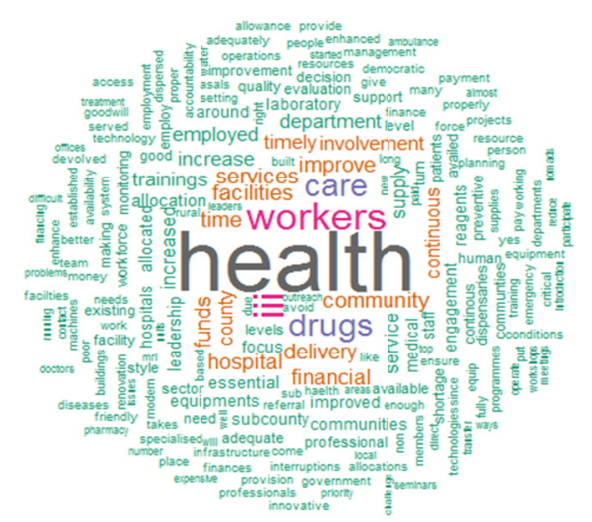

Figure 5. Word Cloud on Aspects of Healthcare Service Delivery That Have Improved as a Result of Management of devolved health Services

Word cloud on aspects of healthcare service delivery that have improved as a result of management of devolved health services (Figure 5) has delineated timely and continuous workers and community involvement in healthcare service delivery as key aspects that have improved as a result of devolution. Funds to counties and improved health facilities were also noticeable aspects.

\subsubsection{Change in Leadership Style in Health Care Service Delivery}

This section presents a frequency distribution graph on respondents' opinion regarding significance of change in leadership style that they have observed in their respective counties in healthcare service delivery (Figure 6). The section also presents a bar plot of most occurring adjectives on predominant leadership style within their respective counties (Figure 7) as well as a word cloud on (predominant leadership style in respondent's respective county (Figure 8). 


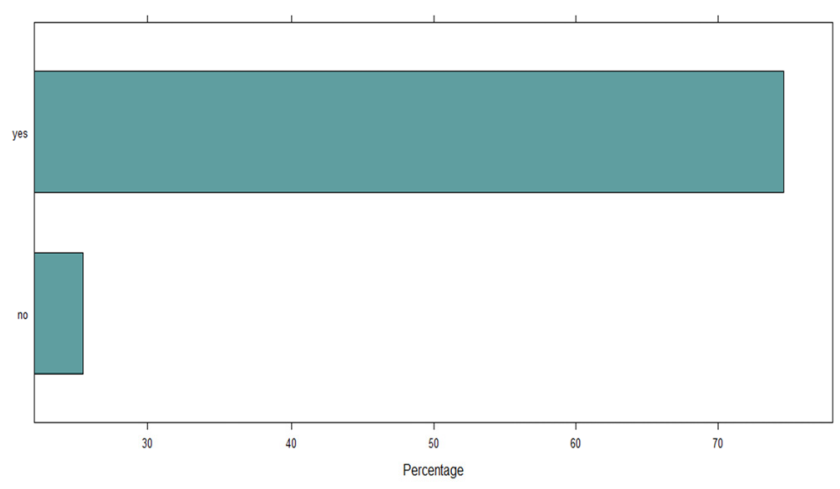

Figure 7: Whether there has been any significant change in leadership style in healthciare service delivery

As shown in Figure 7, over 70 percent of respondents were of the opinion that there has been significant change in leadership style in healthcare service delivery with less than $30 \%$ negating this. This implies that majority of healthcare facilities in ASAL have experienced a significant change in leadership style in healthcare service delivery as a result of management of devolved health services.

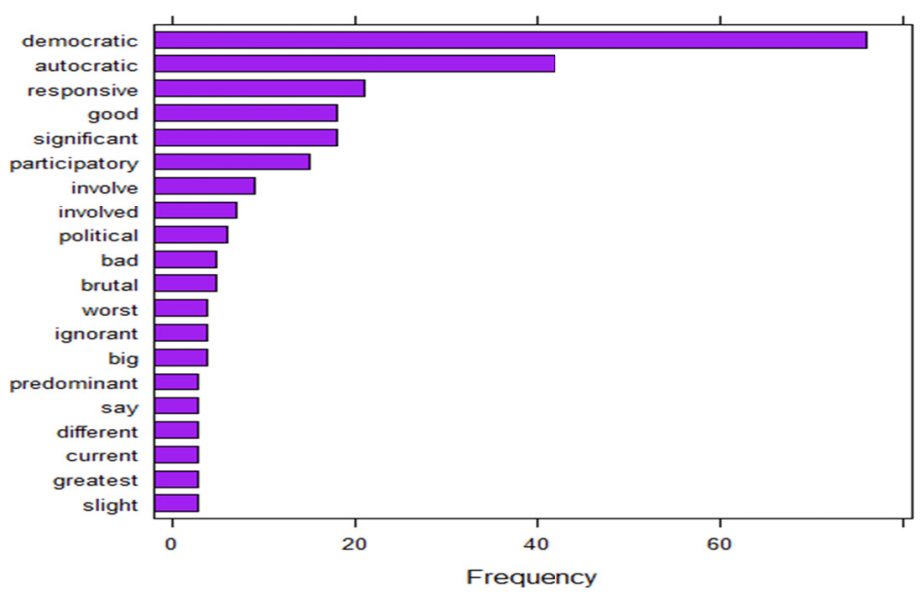

Figure 8. Bar Plot of most occurring adjectives on predominant leadership style in respondent's respective county

As shown in Figure 8, the most occurring word was "democratic" with over 60 mentions followed by "autocratic" (at least 40 mentions) as well as "responsive, good, significant and participatory" with each having at least 20 mentions). Fewer than ten mentions were found on words such as slight, greatest, current, say, predominant, big, ignorant, worst, worst, brutal and bad. This implies that, since introduction of devolved governments, decentralized leadership has gradually changed from autocratic to democratic with residents allowed to participate in decision making which has eventually yielded responsive and significance outcome. 


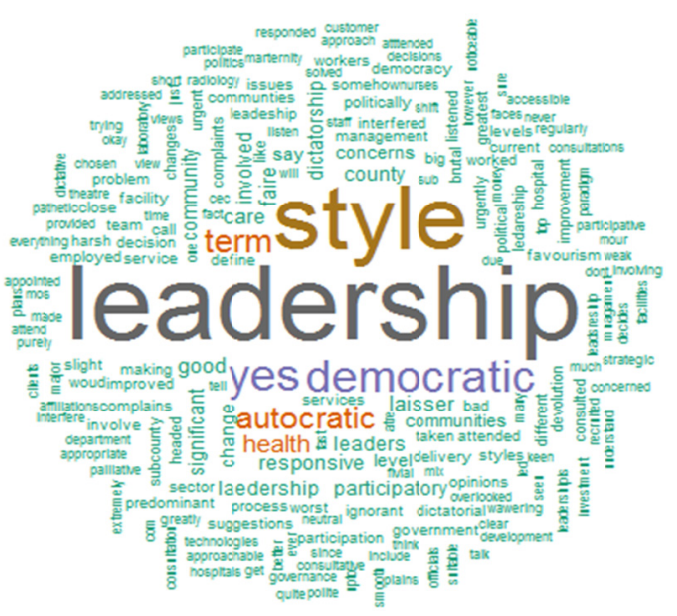

Figure 9. Word cloud on predominant leadership style in respondent's respective county

Bar plot of most occurring adjectives on predominant leadership style (Figure 7) places democratic, autocratic as the most prevailing leadership styles in ASAL with various other adjective (including responsive, good, significant, participatory and involved) only endorsing pronounced levels of democratic leadership style. Despite this, respondents described a few instances of "brutal, worst, ignorant, and political" leadership styles in the process of healthcare service delivery in their respective counties Figure 9 is an elaboration of these findings using word cloud illustration.

\section{Findings and Discussion}

The study found that, management of devolved health services has a unique significant and positive contribution to healthcare service delivery regardless of its interaction with democratic leadership style ( $p$-Value $<0.05$ for both models). The same case applied to democratic leadership style which has significant influence on healthcare service delivery but only when interacted with the other predictor, that is management of devolved health services $(\mathrm{b}=1.274, \mathrm{p}$-Value $=0.015<0.05)$. This effect can be explained by the "I share" philosophy in democratic leadership where decisions are made within teams, with each member having equal inputs. Democratic leadership style is that involves all members of a team in identifying essential goals and developing procedures or strategies for reach those goals. From this perspective, democratic leadership can be seen as a leadership styles that relies heavily on the leader functioning as a facilitator rather than simply issuing orders or making assignments. This type of involved leadership style can be utilized in business settings, volunteer organizations and even in the function of the home.

One of the main benefits of democratic leadership as argued by Daft (2014) is that the process allows for the development of the additional leaders who can serve the organization at a later date. Because leaders who favor this style encourage active involvement on the part of everyone on the team, people often are able to express their creativity and demonstrate abilities and talents that would not be made apparent otherwise that ultimately improve the performance of employees. The discovery of these hidden assets help to benefit the work of the current team, but also alerts the organization to people within the team who should be provided with opportunities to further develop some skill or ability or future use. The Democratic Leader acts to value inputs and commitment via participation, listening to both the bad and the good news (Lewin et al, 1939). Smith (1998) asserted that the democratic leaders have a good relationship with the employee resulting to high employee performance.

Anderson (1991) also described that democratic leaders as one who shares decision making with the other members and therefore, democratic leadership is connected with higher morale. He denied that democratic leadership is associated with low productivity and high morale and that authoritarian leadership is associated with high productivity and low morale. Daft (2014) also argued that democratic leader delegates authority to others to encourages to make employee own decisions and mostly relies on subordinates' knowledge to complete the task. The subordinates have a greater say in decision-making, determination of policy, implementation of systems and procedures (Mullins, 2007). Jooste and Fourie (2009) argued that democratic leadership leads to improved productivity and job satisfaction. Democratic The most effective leadership style is one that leads to higher productivity, better contributions from subordinates, and increased group morale (Anderson, 1991). Under 
democratic leadership, the superiors allow the subordinates to use their abilities to initiative and make contributions (Anderson, 1991). The leaders also offer support to the subordinates in accomplishing tasks (Igbaekemen \& Odivwri, 2015). In this style, managers' enable employees to make suggestions and recommendations on major issues and give subordinates full control and responsibility for those tasks, encourage subordinates to become good leaders and involved in leadership and employee development (Iqbal et al 2015). This style provides confidence to employees who will help them to meet deadlines, and departmental goals, to provide efficient team inputs (Iqbal et al, 2015).

It is important to note that leadership style greatly determines the impact of county leadership in terms of accountability in ensuring efficiency of healthcare service provision. Khemani (2006) warns that, leadership style that does not encourage stakeholders' involvement can be counterproductive to devolved units as this leads to de-motivation, lack of ownership and encouraged corruption among local authorities. A study by Munga et al (2009) revealed that continuous interference by central government in local recruitment issues in Tanzania reduced the autonomy of local authorities, thus leading to reduced effectiveness in the decentralized management. Mkoka et al (2014) also adds that, challenges experienced in devolution can highly be associated with leadership issues including shortage of health workers, unclear mechanisms for accountability, lack of incentives to motivate overworked staff and lack of partnership for development.

Findings in this study also confirms that, devolution has empowered the county government to design innovative models that suit the terrain of their unique sector needs; sufficient scope to determine health system priorities; and allow the authority to make autonomous decisions on sub-sector resource allocation and expenditure (Kenneth, 2014 as cited by Gaogallo, 2015). This can happen if devolution process has been fully embraced by all the implementing stakeholders. If devolution has not been fully implemented, then its effect may not be fully experienced in sectors such as health (Muchomba \& Karanja, 2015). It has been found also that devolution provides an opportunity to rationalize the service delivery framework in Kenya for increased efficiency and accountability. This will be achieved by making counties the hub for organizing services at the local level (Khaunya, Wawire, \& Chepng'eno, 2015). A report by KPMG (2014) states that the success of management of devolved health care services in Kenya depends to a great extent on the presence of an enabling environment, an environment that is marked by the will and commitment of all health stakeholders.

Because democratic governance is traditionally defined as occurring by, for and with the public, the boundaries between public agencies, elected officials and the public are inherently complex and contested. Many anxieties about the practice and theory of public participation are related to how democratic governance is conceptualized and how that affects the nature of participation. This is especially important in polities, such as the United States, which are characterized by significant inequalities, sharply divided public opinion on many issues, intensely partisan politics, powerful organized interests and numerous veto points built into the system (Jacobs 2014).

Effective participatory processes require skilled facilitation (Holmes, 2011); however, many of the staff working with public groups lack the knowledge and skills necessary to effectively facilitate participatory processes (Lukensmeyer et al., 2011) and are often the youngest and least experienced employees in the agency (Nabatchi \& Leighninger, 2015). Other concerns regarding stakeholders' participation relate to representation and power dynamics, that is, who is allowed to participate, the extent to which they influence decisions, and how the balance of power influences these (Quick and Bryson, 2016). Exclusion and equality remain concerns of participatory processes (Quick \& Bryson, 2016) as some processes may reinforce existing power imbalances by discouraging minority representation (Dasgupta \& Beard, 2007; Crow et al., 2016) or may be particularly difficult for lay stakeholders to navigate (Endres, 2009).

Other concerns regarding stakeholders' participation relate to representation and power dynamics, that is, who is allowed to participate, the extent to which they influence decisions, and how the balance of power influences these (Quick \& Bryson, 2016). Exclusion and equality remain concerns of participatory processes (Quick \& Bryson, 2016) as some processes may reinforce existing power imbalances by discouraging minority representation (Dasgupta \& Beard, 2007; Crow et al., 2016) or may be particularly difficult for lay stakeholders to navigate (Endres, 2009). Participation more broadly may encourage those involved to become overly focused on short-term actions while ignoring the bigger picture (Lee et al., 2015).

Such activities may include workshops, advisory committees, and task forces, although no single process is best suited to all circumstances (Fung, 2006; Tippett et al., 2007). The specific participatory process used to engage stakeholders depends on a number of contextual factors (Rowe \& Frewer, 2000), which may include the goals of the process, that is, whether stakeholders' participation is seen as an end in itself or as a means to an end ( Wiedemann \& Femers, 1993); who the process is targeted toward (e.g., the general public, a specific subset of 
the public or key stakeholder groups) (Quick \& Bryson, 2016); the history of cooperation or conflict among stakeholder groups and decision makers; and the technical or social complexity of the issue (Bryson et al., 2013). The process chosen and the way it is conducted often indicate whether authorities have a genuine interest in implementing any stakeholders' recommendations or whether the process is merely meant to placate stakeholders (Rowe \& Frewer, 2000).

\section{Conclusion and Recommendations}

Given the findings, did not accept the null hypothesis (H0) and therefore concludes that democratic leadership style has a significant moderating effect on the relationship between management of devolved health services and health-care service delivery in Arid and Semi-Arid Lands in Kenya. Therefore, hospitals management should come up with strategies that can help improve financial resources to fund facilities improvement and purchase of equipment and supplies. These strategies can include seeking for donor funding among others. In addition, the study recommends that hospitals should adopt information technology as a way or reducing cost of service delivery and the extra finances can be directed towards equipment and facilities improvement and acquisition.

In addition, county leaders and in particular those in health docket should allow improvement of interpersonal relationship between the health workers and the management team to ensure increased productivity. In addition, there should be a free flow of information to ensure cohesion. Moreover, the staff should be involved in the process of decision making to ensure strict compliance. Leaders shouldn't just trust on their own decisions. This should also be complemented by health management team having the welfare of the workers at heart besides creating a work environment that will enhance workers participation in the delivery of healthcare services. Over and above, subordinates in the department of health should be adequately educated about the need for harmony with them and their leaders in the work place for the mutual benefit of both parties. This calls for improved communication. The flow of communication from top hierarchy downwards should be smooth in order to avoid unnecessary misinformation which might result into damaging effects on an organization's output.

\section{Acknowledgments}

My sincere gratitude goes to my family and friends for the support they accorded me in my study. My special thanks go to my Ph.D. classmate Mohamud Gedi for his constant encouragement not to give up. I also express earnest appreciation to my supervisors Dr. Shadrack Jirma and Professor Elijah Siringi because they have assisted me in providing direction and guidance. My special thanks also go to the entire teaching and non-teaching staff in the School of Management and Leadership whose contribution and support has helped me to reach this far in my studies. God bless you All.

\section{References}

Abe, T., \& Monisola, O. J. (2014). Citizen Participation and Service Delivery at the Local Government County Government Level: A Case of Ise/Orun Local Government County Government in Ekiti State, Nigeria. Journal of Law, Policy and Globalization, 27, 102-110.

Adam, R., Bays, P. M., \& Husain, M. (2012). Rapid decision-making under risk. Cognitive Neuroscience, 3(1), 52-61. https://doi.org/10.1080/17588928.2011.613988

Ansari, U., Cockcroft, A., Omer, K., Ansari, N. D., Khan, A., Chaudhry, U. U., \& Andersson, N. (2011). Devolution and public perceptions and experience of health services in Pakistan: linked cross sectional surveys in 2002 and 2004. BMC Health Services Research, 11, $2 \mathrm{~S} 4$. https://doi.org/10.1186/1472-6963-11-S2-S4

Ariola, M. M. (2006). Principles and Methods of Research. Manila: Rex Book Store.

Batley, R. (2004). The politics of service delivery reform development and change. The Journal of Global Health Care Systems, 35(1), 23-34. https://doi.org/10.1111/j.1467-7660.2004.00341.x

Briscombe, B., Suneeta, S., \& Margaret, S. (2010). Improving Resource Allocation in Kenya's Public Health Sector. Washington, DC: Futures Group, Health Policy Initiative, Task Order 1.

Cheshire, K. (2010). Decentralization of Health Care Systems as a strategy to increase access to medicines in the developing world. $\quad$ Retrieved from https://accesstomedicineseminar.files.wordpress.com/2010/05/karen-term-paper.pdf.

Dasgupta, A., \& Beard, V. A. (2007), Community driven development, collective action and elite capture in Indonesia. Development and Change, 38(2), 229-249. https://doi.org/10.1111/j.1467-7660.2007.00410.x 
Diana, A., Hollingworth, S. A., \& Marks, G. C. (2014). Effects of decentralisation and health system reform on health workforce and quality-of-care in Indonesia, 1993-2007. International Journal of Health Planning and Management. https://doi.org/10.1002/hpm.2255

Fung, A. (2006). Varieties of participation in complex governance. Public Administration Review, 66 (S1), 66-75. https://doi.org/10.1111/j.1540-6210.2006.00667.x

Government of Kenya. (2014). Options for Kenya's Health Financing Systems. A Policy Brief, Nairobi: Ministry of Health.

Jongudomsuk, P., \& Srisasalux, J. (2012). A decade of health-care decentralization in Thailand: what lessons can be drawn? WHO South-East Asia Journal of Public Health, 1(3), 347-356. https://doi.org/10.4103/2224-3151.207031

Jooste, C., \& Fourie, B. (2009). The role of strategic leadership in effective strategy implementation

Khaunya, M. F., Wawire, B. P., \& Chepng'eno, V. (2015). Devolved governance in Kenya: Is it a false start in democratic decentralization for development? International Journal of Economics, Finance and Management, 4(1).

Kothari. (2012). Research Methodology. Methods and Techniques.

KPMG. (2015). Management of devolved healthcare Services in Kenya.

Lobao, L., Martin, R., \& Rodrigeuz-Pose, A. (2009). Editorial: rescaling the state new modes of institutional-territorial organisation Cambridge Journal of Regions, Economies and Societies, 2, 3-12. https://doi.org/10.1093/cjres/rsp001

Lowe, G. (2012). How employee engagement matters for hospital performance. Healthcare Quarterly, 15(2), 29-40. https://doi:10.12927/hcq.2012.22915

Martinez-Vazquez, J., \& McNab, R. (2003). Fiscal decentralization and economic growth. World Development, 31(9), 1597-1616. https://doi.org/10.1016/S0305-750X(03)00109-8

Milicevic, M.S., Vasic, M., \& Edwards, M. (2015). Mapping the governance of human resources for health in Serbia. Health Policy, 2015, 119(12), 1613-1620. https://doi.org/10.1016/j.healthpol.2015.08.016

Mongkol, K. (2011). The Critical Review of New Public Management Model and its Criticisms. Research Journal of Business Management, 5(1), 35-43. https://doi.org/10.3923/rjbm.2011.35.43

Murkomen, O. K. (2012). Devolution and the Health System in Kenya. Strategic Thinkers and Actors Consultants Ltd., Nairobi.

Nannyonjo, J., \& Oko, N. (2013). Decentralization, Local Government Capacity and Efficiency of Health Service Delivery in Uganda. Journal of African Development, 15(1), 125-158.

Nuguid, N. A. (2011). Devolution. How will the family planning program be affected when local governments get greater autonomy? Integration, (35), 26-27.

Nunnally, J. C. (1978). Psychometric theory. (2nd ed.). New York: McGraw-Hill.

Nzinga, J., Lairumbi, P., \& Mike, A. (2013). Documenting the experiences of health workers expected to implement guidelines during an intervention study in Kenyan hospitals. Implementation Sci., 4(44). https://doi.org/10.1186/1748-5908-4-44

Okech, C. T. (2017). Devolution and universal health coverage in Kenya: situational analysis of health financing, infrastructure \& personnel, International Journal of Economics, Commerce and Management, 4(5).

Olatona, J. B., \& Olomola, P. A. (2015). Analysis of Fiscal Decentralization and Public Service Delivery in Nigeria. Journal of Economics and Sustainable Development, 6(9).

Quick, Kathryn S. \& Martha S. Feldman (2011). Distinguishing participation and inclusion. Journal of Planning Education and Research, 31(3), 272-290. https://doi.org/10.1177/0739456X11410979

Saifuddin, A. (2009). Methods in Sample Surveys. The Johns Hopkins University and Saifuddin Ahmed.

Shiraz, S., Imran, N., Asaad, N., Aysha. Z., Zafar, F. \& Ambreen, K. (2013). Experience of devolution in district health system of Pakistan: Perspectives regarding needed reforms. Journal of Pakistan Medical Association, 62, 68-78.

Sihanya, B., (2013). Presidentialism and Administrative Bureaucracy: 1963-2013, Innovative Lawyering \& Sihanya Mentoring, Nairobi \& Siaya. 
The World Bank. (2012). World Bank Fiscal Decentralisation Knowledge Programme.

Voon, M. L., Lo, M. C., Ngui, K. S., \& Ayob, N. B. (2011). The influence of leadership styles on employees' job satisfaction in public sector organizations in Malaysia. International Journal of Business, Management and Social Sciences, 2(1), 24-32.

Wangari, T. M. (2014). Factors Influencing Citizens'satisfaction With Service Delivery: A Case Of Murang'a County, Kenya. Unpublished MSc Project, Nairobi: The University of Nairobi.

West, M., Armit, K., Loewenthal, L., Eckert, R., West, T. \& Lee, A. 2015. Leadership and leadership development in healthcare: The evidence base Retrieved from http://www.kingsfund.org.uk/publications/leadership-and-leadership development-health-care

Woods, K. J. (2004). Political devolution and the health services in Great Britain. International Journal of Health Services: Planning, Administration, Evaluation, 34(2), 323-339. https://doi.org/10.2190/TTJP-FLC3-2DGM-JNE9

Yusoff, M. A., Sarjoon, A., Awang, A., \& Efendi, D. (2016). Conceptualizing Decentralization and its Dimensions. International Business Management, 10(6), 692-701.

\section{Copyrights}

Copyright for this article is retained by the author(s), with first publication rights granted to the journal.

This is an open-access article distributed under the terms and conditions of the Creative Commons Attribution license (http://creativecommons.org/licenses/by/4.0/). 